\title{
VII
}

\section{DIVERSIDADE CULTURAL NA AMAZÔNIA: DESAFIOS E PERSPECTIVAS*}

\author{
Lucas de Vasconcelos Soares' \\ Maria Lilia Imbiriba Sousa Colares \\ Karolina Carvalho do Amarante 3 \\ Gilberto César Lopes Rodrigues ${ }^{4}$
}

\section{Introdução}

O estudo visa analisar a Diversidade Cultural na região amazônica do Brasil, identificando, a partir do entendimento teórico-conceitual e político-educacional, práticas e desafios presentes nessa realidade. Por conseguinte, discutem-se algumas proposições em torno do tema.

Dos objetivos propostos, buscou-se compreender o arcabouço teórico-conceitual e político-educacional em torno da diversidade cultural, identificando realidades e desafios no âmbito da Amazônia Brasileira e contribuindo com proposições em busca do reconhecimento e da organização coletiva perante a garantia do direito público.

As discussões são fruto de pesquisa bibliográfica e documental, contemplando, entre as técnicas de coleta de dados, o uso de levantamento teórico, selecionando experiências de estudos já realizados; e

\footnotetext{
${ }^{*}$ DOI - 10.29388/978-65-86678-45-1-0-f.155-180

${ }^{1}$ Mestrando em Educação pelo Programa de Pós-graduação em Educação (PPGE) da Universidade Federal do Oeste do Pará (Ufopa). Graduado em Pedagogia pela Ufopa. Bolsista CAPES. E-mail: lu.cas.soares@bol.com.br.

${ }^{2}$ Doutora e Pós-doutora em Educação pela Universidade Estadual de Campinas (Unicamp). Professora do curso de Pedagogia, do Programa de Pós-graduação em Educação (PPGE) e do Programa de Pós-graduação em Educação da Amazônia (PGEDA), na Ufopa. Bolsista de produtividade em pesquisa CNPq, Nível 2. E-mail: lilia.colares@hotmail.com.

${ }^{3}$ Mestranda em Educação pelo Programa de Pós-graduação em Educação da Universidade Federal do Oeste do Pará. Graduada em Pedagogia pela Ufopa. E-mail: karol mak@yahoo.com.br.

${ }^{4}$ Doutor em Educação pela Universidade Estadual de Campinas (Unicamp). Docente do Programa de Pós-graduação em Educação (PPGE) da Ufopa. E-mail: gilbertocesar@gmail.com.
} 
análise documental, em legislações, políticas e relatórios direcionados ao tema, partindo do cenário nacional para o local.

Do embasamento teórico utilizado, o estudo apropria-se, inicialmente, das discussões de Colares (2018), Gomes (2003), Laraia (2001) e Sanfelice (2016), seguido por outros estudiosos do tema. Além destes, contemplam-se importantes documentos de base legal: Constituição Federativa da República do Brasil de 1988, dentre outros.

Para efeito de organização, o artigo está composto por duas partes: definições teórico-conceituais e políticas da diversidade, compreendendo as origens formativas do termo "Diversidade Cultural" e sua incorporação nos documentos de base legal; e espaços de diversidades, destacando as realidades presentes na região, com ênfase nas práticas e desafios postos a consolidação do direito público.

\section{Definições teórico-conceituais e políticas da diversidade}

A temática da diversidade cultural ainda é bastante complexa e tem ocupado centralidade nas agendas políticas de diversos países (MUNANGA, 2014). Discute-se sobre a importância do tema nas esferas econômica, política, social, cultural e educacional, uma vez que o debate tem sido fortalecido pela reflexão das inúmeras diferenças existentes na sociedade contemporânea e suas relações instituídas ao longo da história, clareando realidades deficitárias no que se refere a garantia do direito público, permeadas por visões eurocêntricas, conflitos e resistências. Em um primeiro momento, recorremos a uma compreensão teóricoconceitual dos termos "Diversidade" e "Cultura" em busca da definição de um conceito aproximado ao tema em questão, pois, a própria literatura é divergente com relação a isso. Posteriormente, identificamos legislações e políticas instituídas no país, direcionadas à questão da diversidade cultural, nomeadas neste estudo como Políticas da Diversidade.

Em posse de uma definição dicionarizada, destaca-se que o conceito de Diversidade implica "qualidade ou condição do que é diverso; diferença, dessemelhança; divergência, contradição; multiplicidade de coisas diversas, existência de seres ou entidades não idênticos". Já a palavra Cultura é apresentada como "conjunto dos hábitos sociais e religio- 
sos, das manifestações intelectuais e artísticas, que caracteriza uma sociedade; normas de comportamento, saberes, hábitos ou crenças que diferenciam um grupo de outro". Concomitantemente, define-se a Diversidade Cultural como um "conjunto de características culturais que, observadas em pessoas circunscritas num mesmo espaço geográfico, caracteriza costumes, hábitos sociais ou crenças que variam de uma pessoa para outra" (Dicionário On-line de Português, 2009).

Desse modo, entende-se que a Diversidade Cultural é constituída pela existência de várias formas de culturas presentes e diversas entre si em uma mesma realidade. Essa pluralidade se manifesta em diferentes formas de ser, pensar e agir da condição humana sobre o meio ao qual está inserido, utilizando-se das linguagens, tradições, comportamentos, crenças, valores, estilos, etc., como instrumentos de produção/apropriação/reprodução de culturas ao longo da vida. Assim, podemos compreender que ao falar de diversidade cultural, nos colocamos diante de variados produtos históricos, sociais, culturais e intelectuais, frutos da intervenção humana, repassados no decorrer dos anos de geração em geração.

Cada grupo social dispõe de um estilo próprio de vida, consolidando uma infinidade de expressões culturais na sociedade, visto que tais diferenças são responsáveis pela singularidade que existe em cada indivíduo, integrantes do todo social. Consequentemente, o conjunto de singularidades forma uma cultura própria, responsável por diferenciar grupos sociais e realidades. Nesse contexto, estudiosos do tema, entre eles antropólogos e historiadores, tratam do complexo conceito de cultura, com destaque para os trabalhos de Santos (1987), Chauí (2000) e Laraia (2001).

De acordo com Santos (1987), o termo Cultura está associado às atividades agrícolas, oriundo do verbo latino colere (cultivar), destacando que “[...] há séculos o conceito de cultura foi objeto de preocupação de vários estudiosos, em busca de compreender as variações de culturas e as razões da variedade das culturas humanas ao longo do tempo" (SANTOS, 1987, p. 7). Portanto, fica clara a inviabilidade de compreensão da cultura sem a utilização da história que permeia o processo de evolução dos grupos humanos e suas transformações no meio social. 
Segundo Chauí (2000, p. 352), o tratamento da antropologia sobre o termo cultura define-o como um "[...] modo de vida global de uma sociedade, incluindo: religião, formas de poder, [...] parentesco, [...] comunicação, organização da vida econômica, artes, técnicas, costumes, crenças, formas de pensamento e de comportamento, etc. [...]". Guiando-se no mesmo campo de investigação (antropológico), Laraia (2001) ressalta que as diversidades culturais não são resultantes de diferenças biológicas e/ou geográficas. De acordo com o autor, a primeira definição do conceito de cultura é datada de 1981 por Edward Tyler (1832-1917), antropólogo britânico que sintetizou os termos Kultur, atribuído a aspectos espirituais (de origem germânica no século XVIII), e Civilization, de realização material (com origem francesa no século XVIII), para o vocábulo inglês Culture, indicando que este se trata de "[...] todo complexo que inclui conhecimento, crenças, arte, moral, leis, costumes ou qualquer outra capacidade ou hábitos adquiridos pelo homem como membro de uma sociedade" (LARAIA, 2001, p. 27) que independem de uma transmissão genética.

Todavia, é importante lembrar que o termo já vinha sendo objeto de preocupação por vários estudiosos, como John Locke (1632-1704), autor responsável pela criação da endoculturação, cujo processo se dá na obtenção de conhecimentos por meio de um aprendizado, e defensor do relativismo cultural que significa, na visão antropológica, a forma de ver diferentes culturas livre de etnocentrismo, ou seja, sem julgamento.

Historicamente, a origem da cultura aparece simultaneamente com o desenvolvimento do equipamento biológico humano. Esse processo evolutivo foi resultado das transformações de sobrevivência que surgiu com as habilidades manuais. Tal habilidade foi possibilitada pela posição ereta que proporcionou estímulos ao cérebro, segundo estudiosos, tornando-o mais volumoso e complexo (LARAIA, 2001). O autor cita dois exemplos, embasado por outros autores, sobre o termo: 1) $\mathrm{Na}$ visão de Lévi-Strauss, a cultura surgiu a partir do momento que o homem convencionou a primeira regra, como a proibição do incesto; 2) Para Leslie White, a cultura surge quando o homem foi capaz de gerar símbolos, como por exemplo, na questão do luto, simbolizado pela cor preta no Brasil e pela cor branca na China (LARAIA, 2011). 
Corroborando ao entendimento sobre a origem e definição da cultura, trazemos o estudo de Borges (2017) a respeito dos conceitos de trabalho e humanização em Marx, Engel e Lukács. É desta mesma autora a afirmativa de que "[...] ao interagir de forma determinada com a natureza, o homem foi capaz de se diferenciar do mundo natural e, em paralelo, criar outro mundo, ou seja, o mundo da cultura, o mundo humano" (BORGES, 2017, p. 102). Brotam desse entendimento os primeiros indícios sobre a ontologia do ser social, ou seja, a partir do momento em que o homem produz sua cultura, este se distancia da natureza, mas sem abandoná-la. Nesse processo de ruptura, a interação humana com a natureza é dada pela necessidade de sua sobrevivência, por meio da ação consciente, possibilitada pelo trabalho. Assim, é vislumbre a passagem da ação natural para a ação social. Portanto, as ações humanas resultam de processos de aprendizagens, transmitidas nas relações sociais de uma determinada cultura.

Para Laraia (2001), a cultura determina a maneira de vermos o mundo, possibilitando visões diversas e desencontradas sobre as coisas, sendo um elemento dinâmico e, ao mesmo tempo, mutável, pois, condiz com o tempo e o contexto em que é constituído. Na sociedade cada cultura dispõe de uma lógica própria (de organização, valores, etc.), o que gera muitos embates entre as diferentes realidades sociais, visto que, a partir de uma visão etnocêntrica, o homem subjuga o outro em detrimento de sua cultura, considerando-se superior. Dessa forma, infere-se que o modo de ser, de conviver, o tipo de relação familiar, entre outros fatores, é fruto das relações e interações entre as culturas. No entanto, nem sempre este processo ocorreu/ocorre de forma harmônica, uma vez que, no decorrer da história, são visíveis as marcas de conflitos e resistências entre diferentes culturas e grupos humanos.

Nas discussões apresentadas por Santos (1987), a diversidade cultural e seus embates constitui-se como um dos pontos chaves para se compreender os inúmeros preconceitos de cor, raça, etnia, sexo, religião, etc., condizendo na construção de pensamentos e lógicas próprias de determinada cultura para impor-se, de forma superior e dominante, sobre outras. Tal ação decorre da naturalização de ideias, comportamentos e valores oriundos dos povos colonizadores, processo gerador dos fenô- 
menos de racismo, discriminação, preconceito, genocídio, xenofobismo e outros, tornando as relações humanas conflituosas. No âmbito da contradição, significa dizer que a humanidade se constituiu a partir de desumanidades.

Esse pensamento figurou no Brasil, com ênfase durante o processo de colonização, principalmente, com a chegada dos portugueses e jesuítas em terras indígenas, em busca de riquezas, dominação e com a proposta de "salvação das almas" (COLARES, 2018), impondo a cultura colonizadora como a saída para os nativos, condenando seus estilos e modos de vida. Soma-se a este, o tráfico negreiro, ocorrido no período da escravidão, onde os negros eram sequestrados, arrancados de suas raízes e direcionados a destinos incertos, desconhecidos, sendo obrigados a abandonar sua cultura em detrimento de outra (MUNANGA, 2003). Fruto destes acontecimentos, a diversidade de culturas, de base negra e indígena, historicamente foi sendo invisibilizada na sociedade, subjugadas pela dominação colonial europeia que instituiu paradigmas socioculturais no país, negando as demais (SOARES; MELO, 2017).

O Brasil, considerado um país com uma diversidade cultural heterogênea, característica central do povo brasileiro, visível nas mais variadas regiões geográficas, manifestações culturais e linguísticas, tradições, culinárias, danças, costumes, lendas, religiosidades, etc., tem se firmado no contexto da contradição de sua própria história. Desde as culturas pioneiras identificadas no país, indígenas, africanas e europeias, seguido por imigrantes asiáticos, alemães, italianos, entre outros, formou-se uma enorme teia de povos miscigenados, espalhados por todos os cantos do país, figurando uma multiplicidade de culturas em cada região, estados e/ou município, que foram firmando-se mediante um cenário político de tensões e conflitos.

Na região amazônica, lócus central do estudo, é visível um espaço com rica biodiversidade, de natureza exuberante e que tem sido explorada pelos avanços desenfreados da onda neoliberal, esmaecendo o contexto humano em prol do acúmulo de riquezas e poder. Nesse cenário, residem povos de culturas diversas, entre eles: ribeirinhos, quilombolas, indígenas, povos da floresta, nordestinos, etc., que necessitam de respeito, 
reconhecimento, preservação e valorização social (COLARES, 2018). Para este mesmo autor, a diversidade amazônica se faz presente:

[...] tanto entre os habitantes nativos quanto a que resulta da presença cada vez mais intensa de migrantes. Na mistura de etnias e de culturas, foi se constituindo a Amazônia humana, para além do exuberante território que desde os primeiros contatos do colonizador representou grandes possibilidades de ganhos econômicos, e que estão expressas nos diversos ciclos tais como o extrativista com as drogas do sertão, o da borracha [...], entre outros (COLARES, 2018, p.13).

Mediante o contexto descrito sobre a Diversidade Cultural no país, adentra-se no campo político-educacional em busca de uma compreensão sobre o processo de organização deste termo e sua incorporação como direito público na legislação vigente. Inicialmente, destaca-se que, a partir das ações internacionais da Organização das Nações Unidas para Educação, a Ciência e a Cultura (Unesco), desde sua fundação em 1945, foram se intensificando e ajustando os debates sobre a diversidade cultural, pautados no propósito de estabelecer um diálogo cooperativo entre as inúmeras culturas por meio do respeito mútuo e de valores compartilhados (DUPIN, 2009). Posteriormente, surge a Declaração Universal sobre a Diversidade Cultural (UNESCO, 2001), da qual o Brasil é signatário, considerando, de acordo com o Artigo $1^{\circ}$, a diversidade cultural como patrimônio comum da humanidade, adquirida de diversas formas historicamente e por um determinado lugar, manifestada na pluralidade de identidades que caracterizam um grupo e a sociedade, necessárias ao convívio humano e que merecem ser reconhecidas em prol das futuras gerações (UNESCO, 2001). Corroborando a garantia de um direito público, o Artigo $2^{\circ}$ define que:

Art. $2^{\circ}$. Nas nossas sociedades cada vez mais diversificadas, tornase indispensável garantir a interacção [sic] harmoniosa e a vontade de viver em conjunto de pessoas e grupos com identidades culturais plurais, variadas e dinâmicas. As políticas que favorecem a inclusão e a participação de todos os cidadãos garantem a coesão so- 
cial, a vitalidade da sociedade civil e a paz. [...] desta forma, o pluralismo cultural constitui a resposta política à [...] diversidade cultural. Inseparável de um contexto democrático, o pluralismo cultural é propício aos intercâmbios culturais e ao desenvolvimento das capacidades criadoras que nutrem a vida pública (UNESCO, 2001).

Outra atuação da Unesco se deu na construção do documento referente à Convenção sobre a Proteção e Promoção da Diversidade das Expressões Culturais, ocorrida em 2005 em Paris, ratificado no Brasil pelo Decreto Legislativo No 485/2006. Notoriamente, apresenta-se uma definição ao termo diversidade cultural, afirmando que:

Art. $4^{\text {o }}$. Diversidade cultural refere-se à multiplicidade de formas pelas quais as culturas dos grupos e sociedades encontram sua expressão. Tais expressões são transmitidas entre e dentro dos grupos e sociedades. A diversidade cultural se manifesta não apenas nas variadas formas pelas quais se expressa, se enriquece e se transmite o patrimônio cultural da humanidade mediante a variedade das expressões culturais, mas também através dos diversos modos de criação, produção, difusão, distribuição e fruição das expressões culturais [...] (UNESCO, 2007).

No contexto legal e normativo brasileiro, as discussões sobre a diversidade constam na Constituição Federativa da República de 1988, especificamente, em seu artigo $3^{\circ}$ que, dentre os objetivos fundamentais, visa "IV - promover o bem de todos, sem preconceitos de origem, raça, sexo, cor, idade e quaisquer outras formas de discriminação" (BRASIL, 1988). No âmbito da cultura, consta no Artigo 215 que é dever do Estado garantir os direitos culturais, apoiando e incentivando a valorização e difusão das manifestações culturais no país (BRASIL, 1988), destacando que:

$\mathbb{S} \mathbf{1}^{\mathbf{0}} \mathrm{O}$ Estado protegerá as manifestações das culturas populares, indígenas e afro-brasileiras, e das de outros grupos participantes do processo civilizatório nacional. 
$\$ 2^{\circ}$ A lei disporá sobre a fixação de datas comemorativas de alta significação para diferentes segmentos étnicos [...] (BRASIL, 1988).

No âmbito educacional, as discussões sobre as políticas para a Diversidade Cultural ganham maior ênfase a partir dos anos 1990, no período conhecido como de redemocratização nacional, marcado pela intensificação de movimentos sociais em busca do reconhecimento de direitos no campo público para o combate as diversas formas de discriminação e negação das diferenças entre povos e culturas, visibilizando um lugar, também, no currículo oficial da rede de ensino. Estas reivindicações se davam na proposta de incorporação, no campo pedagógico, da diversidade cultural, voltando-se a valorização das múltiplas culturas, em discussões sobre diferenças, multiculturalismo, interculturalismo, etc.

Antes de qualquer passo, é importante destacar que as conquistas em torno da diversidade cultural não se associam como iniciativas dos governos para a valorização dos povos brasileiros. Pelo contrário, estas se deram num movimento contra-hegemônico, em prol das minorias marginalizadas na sociedade, visando à equidade social e a solidificação de políticas públicas de cunho assistencialista e protecionista, garantindo a participação, democracia, respeito e reconhecimento. Para Munanga (2003), um caminho a ser trilhado, visando combinar igualdade e diversidade em uma convivência harmoniosa, deve ser a associação da democracia política com a diversidade cultural, baseando-se na liberdade do sujeito. Apesar do pessimismo do autor, sabemos que isso raramente acontecerá, uma vez que prevalecem forças ideológicas e opressoras no comando dos órgãos públicos instituídos.

Desse modo, o Quadro de $N^{o} 1$ sistematiza, cronologicamente, as principais políticas educacionais direcionadas à Diversidade Cultural no Brasil, destacando: 
Quadro 1: Principais políticas educacionais da diversidade no Brasil.

\begin{tabular}{|c|c|}
\hline ANO & BASE LEGAL \\
\hline 1988 & Constituição Federativa do Brasil - Art. 205 e 210. \\
\hline 1996 & Lei $\mathrm{N}^{\circ} 9.394 / 96 \mathrm{LDB}-$ Art. $3^{\circ}$ e 26. \\
\hline 1997 & Parâmetros Curriculares Nacionais: Pluralidade Cultural. \\
\hline 2003 & Lei No 10.639/2003: História e Cultura Afro-brasileira no currículo. \\
\hline 2006 & Orientações e ações para a Educação das Relações étnico-raciais. \\
\hline 2007 & Programa Ética e Cidadania (Inclusão social). \\
\hline 2008 & $\begin{array}{l}\text { Lei No 11.645/2008: História e Cultura Afro-Brasileira e Indígena no currí- } \\
\text { culo. }\end{array}$ \\
\hline 2010 & Lei $N^{\circ} 12.288 / 2010$ : Estatuto da Igualdade Racial. \\
\hline 2012 & Lei $\mathrm{N}^{\circ}$ 12.711/2012: Lei de Cotas. \\
\hline 2013 & $\begin{array}{l}\text { Plano Nacional de Implementação das Diretrizes Curriculares para a Educa- } \\
\text { ção das Relações Étnico-raciais e Ensino de História e Cultura Afro-Brasilei- } \\
\text { ra e Africana. }\end{array}$ \\
\hline 2014 & Lei No 13.005/2014: Plano Nacional de Educação - PNE: Art. 2º III e X. \\
\hline
\end{tabular}

Fonte: elaborado pelos autores, 2020.

Além destes, destacam-se a contribuição de outros documentos, como as Diretrizes Curriculares Nacionais Gerais para a Educação Básica, no eixo Diversidade e Inclusão, contendo cinco pareceres ${ }^{5}$, os quais se consolidam em direção ao alcance do acesso à educação por grupos historicamente excluídos das políticas educacionais. É importante frisar que no ano de 2019, já no governo do presidente Bolsonaro (2019-2022), foi extinta a Secretaria de Educação Continuada, Alfabetização, Diversidade e Inclusão (Secadi), órgão atuante na luta pela promoção da igualdade no campo dos direitos.

Ainda no campo educacional, Gomes (2003), Canen (2000), Munanga (2014) e Moreira; Candau (2003) defendem a incorporação da diversidade cultural nos currículos e práticas pedagógicas, argumentando uma educação multicultural na perspectiva da interculturalidade.

\footnotetext{
${ }^{5}$ Parecer $N^{\circ}$ 36/2001: diretrizes operacionais para a educação básica nas escolas do campo; Parecer $N^{o}$ 003/2004: diretrizes curriculares para a Educação das relações étnico-raciais e ensino de história e cultura afro-brasileira e africana; Parecer No 08/2012: diretrizes para a Educação em direitos humanos; Parecer No 13/2012: diretrizes curriculares para a Educação Escolar Indígena; e Parecer No 16/2012: diretrizes curriculares para a Educação Escolar Quilombola.
} 
Na visão de Canen (2000, p. 136), a incorporação de uma educação multicultural implica um olhar mais atento "[...] para a valorização da pluralidade cultural e a necessidade de superar estereótipos, preconceitos e hierarquização cultural em currículos e práticas pedagógicas [...]”, rompendo com a protocolarização de um currículo nacional de base neoliberal. Por outro lado, Munganga (2014, p. 35) ressalta que "[...] sem o reconhecimento da diversidade das culturas, a ideia de recomposição do mundo arrisca-se a cair na armadilha de um novo universalismo", abandonando a ideia do multiculturalismo como proposta de valorização das inúmeras variações culturais. No entanto, é preciso atentar-se para as relações instituídas nas escolas, sendo que estas:

Tanto podem contribuir para a reprodução das formas de conduta, das relações e dos conhecimentos que funcionam como requisitos para a manutenção de um modelo econômico, político, cultural e religioso fundamentado na desigualdade e reforçador das diferenças, quanto podem promover a resistência a este modelo e propor a sua superação. Se a opção desejada estiver na perspectiva transformadora, é imprescindível o conhecimento da diversidade, como pressuposto para o respeito e a valorização (COLARES; COLARES, 2011, p. 3).

No tratamento da relação entre educação e diversidade cultural, Moreira e Candau (2003) destacam que os professores possuem dificuldades em utilizar a cultura como eixo formativo do currículo e incorporá-la nas práticas educacionais reais da escola pública, apontando como solução a desconstrução de um currículo eurocêntrico e o confronto com diferentes pontos de vistas, perspectivas, obras literárias e eventos históricos, contrapondo-se a visão dominante estarrecedora. Defende-se então a proposição de "[...] políticas pedagógicas e metodológicas [...] para a educação [...] incluindo as diversidades" (SOARES; COLARES; FERREIRA, 2020, p. 78).

Portanto, ao tratar da Diversidade Cultural é preciso compreendê-la como "[...] fonte de riqueza material e imaterial, e, em particular, dos sistemas de conhecimento das populações [...] e sua contribuição positiva para o desenvolvimento sustentável, assim como a necessidade 
de assegurar sua adequada proteção e promoção [...]" (UNESCO, 2007, p. 1). Assim, adentra-se num exercício crítico-reflexivo de compreensão, análise e reformulação de visões sobre os povos e suas variações culturais. O próximo tópico pauta-se nesse olhar, discutindo práticas, desafios e perspectivas na Amazônia.

\section{Espaços de diversidades}

A Amazônia Legal, está composta por nove Estados (Acre, Amapá, Amazonas, Pará, Rondônia, Roraima e partes de Mato Grosso, Tocantins e Maranhão) e 775 municípios, incluindo toda a região norte do país, ocupando uma área territorial de $5.217 .423 \mathrm{~km}^{2}$, correspondente a $59 \%$ do território nacional (IMAZON, 2013). É nessa área geográfica que se encontram extensões inimagináveis de rios e florestas, exuberantes diversidades de espécies animais e vegetais e a presença de povos miscigenados situados em seus tempos e espaços. São, aproximadamente, 20,3 milhões de moradores, sendo " 68,9 residentes na área urbana e $31,1 \%$ localizados na zona rural” (IMAZON, 2013), abrigando 12,3\% da população do Brasil. A Figura de $\mathrm{N}^{\mathrm{o}} 1$ representa a delimitação geográfica do lócus do estudo.

Figura 1: Delimitação da área geográfica da Amazônia Legal.

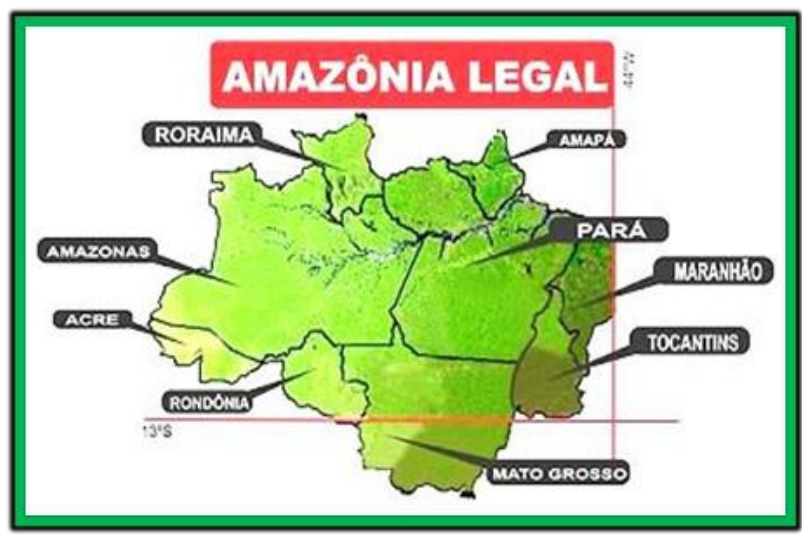

Fonte: https://www.abcdoabc.com.br/brasil-mundo/noticia/governadores-amazonia-firmam-agenda-acordo-europeus-88606, 2019. 
É importante destacar que perdurou por muito tempo, no campo da produção científica, o tratamento da Amazônia como um cenário exótico, potencializador de bens e recursos, propício ao acúmulo de riquezas, de exploração humana pelo trabalho e de embates pelo uso da terra. Na transição do século XX ao XXI é visível uma ampliação nos debates, revelando um caráter humano, pautado nos modos de vida dos povos locais e suas condições de sobrevivência, bem como na divulgação dos conhecimentos, vivências, culturas e saberes tradicionais amazônicos, visível nas discussões de Colares e Colares (2016 ${ }^{6}$ e Colares (2018). Tais estudos sinalizam avanços para a compreensão da diversidade cultural, propondo novas visões sobre a região e contrariando imagens estereotipadas concebidas ao longo de sua história. O exercício de análise do local torna-se significativo, pois, "[...] sem os estudos regionais e locais, o nacional será reduzido a mera abstração ou será tomada como nacional a manifestação local ou regional mais influente [...]" (SAVIANI, 2016, p. 2), contribuindo na redução das inúmeras "[...] distorções que a grande maioria de todos nós, brasileiros ou não, constrói sobre a Amazônia [...] acumulando o desconhecimento puro e simples, as visões míticas e os preconceitos [...]" (SANFELICE, 2016, p. 7).

Uma das principais características da região visibiliza-se nas variações culturais que dotam de significados a vida, a história e constituem a essência do povo amazônico, produzidas e replicadas de geração em geração. Essas diversificações formam a cultura amazônica, manifestada por crenças, saberes, hábitos, conhecimentos e experiências reais próprias, contemplando a "[...] natureza transformada e significada pelo homem [...]” (BRANDÃO, 2002, p. 37).

Guiando-se nessa perspectiva, pensar na diversidade cultural da Amazônia é adentrar num universo de particularidades, na relação entre passado e presente, a fim de compreender os modos e processos de vidas instituídos pelos sujeitos locais e sua disseminação no decorrer do tempo, verificando como esta cultura vem se alterando e/ou mantendose mediante a evolução da sociedade. Em outras palavras, é fundamental o exercício de compreender na história uma explicação para o presente

\footnotetext{
${ }^{6}$ Os autores apresentam importantes contribuições para o enfoque de uma Amazônia humana, utilizando os trabalhos de Violeta Loureiro e Daniel Klein como referências centrais do estudo.
} 
desvelado. No caso da Amazônia, ao propor este caminho nos colocamos diante de um desafio ainda maior, levando em conta a sociodiversidade presente (COLARES; COLARES, 2011) e a condição de que são muitas realidades presentes em uma só, incutindo a ideia de várias "Amazônias" (COLARES, 2018).

Nas discussões de Saviani (2016, p. 1), em um de seus poucos textos que versam sobre a região, destaca-se que "[...] a característica diferencial da região amazônica é, sem dúvida, a presença de uma multiplicidade de povos [...] em seu amplo território, caracterizado pela mais rica biodiversidade do planeta". Concomitantemente, Sanfelice também ressalta uma sociabilidade, menos homogênea, dos povos locais, entre eles:

[...] comunidades de pescadores artesanais, os ribeirinhos, os remanescentes quilombolas, os povos indígenas, os retireiros, os seringueiros, os assentados agrários, os trabalhadores de grandes propriedades agrícolas, os pecuaristas, as ocupações de trabalhadores sem terras, migrantes nordestinos, sulistas e imigrantes de várias partes do mundo [...] (2016, p. 7-8).

Com base nestes dois grandes autores, é possível inferir que estamos diante de um cenário de povos miscigenados, formados a partir da relação entre grupos humanos distintos, caracterizando uma Amazônia multicultural, pluralista, heterogênea e, ao mesmo tempo, singular. No âmbito da própria contradição, significa dizer que:

[...] existe uma acentuada e rica diversidade cultural, e não apenas uma diversidade na nossa composição étnica. Todavia, nem todos atribuem a esta diversidade a mesma importância e a consideram em sua riqueza, na medida em que ainda há quem assuma posição nitidamente enaltecedora de uma determinada cultura em detrimento de outra(s) (COLARES; COLARES, 2011, p. 1).

É visível ainda que, a partir das divergências entre os povos, principalmente, no confronto entre seus modos e processos culturais de vida, aliada a condição excludente da sociedade, inúmeros conflitos passam a figurar no cenário amazônico, refletindo em casos de perseguição, vio- 
lência, injustiças, discriminação, intolerância e outras formas que atentam contra a dignidade da pessoa humana (COLARES; COLARES, 2011).

Outra particularidade, por sinal, deficitária, mostra-se nas condições logísticas da região e seus reflexos nos modos de vida das populações locais que, diariamente, convivem com a ausência de direitos básicos fundamentais: falta de saneamento básico, saúde, educação, segurança, qualidade de vida, etc., principalmente os ribeirinhos que residem às margens de rios. Sob tais indícios de vulnerabilidade social, Sanfelice apresenta uma caracterização sociohistórica desses sujeitos, destacando que:

Grande parte dessa população vive determinada pelo ritmo das águas cheias ou vazantes dos grandes rios. Para aquelas populações a ocupação dos espaços físicos, a organização da temporalidade da produção para a subsistência, as relações sociais de parentesco e comunitárias tornam-se muito específicas. São as diversidades que foram herdadas das tradições, as diversidades já contrárias à tradição e, a diversidade das diversidades [...] (2016, p. 8).

Estes são, portanto, povos que se diferem dos demais pela sua capacidade de organização sociohistórica em prol da sobrevivência, produzindo culturas e estilos próprios de vida, capazes de resistir ao longo de sua história e, ainda que de forma mínima, firma-se no sentido do reconhecimento no campo do direito público.

Nesse sentido, o estudo do contexto local, em realidades como a Amazônia, torna-se fundamental para explicitar as mazelas sociais do Brasil, revelando condições de abandono, descaso e ineficiência dos órgãos e políticas, enfraquecendo o compromisso e o atendimento as minorias. Para Sanfelice, este exercício é válido no sentido de que “[...] todo o particular se explicita em um contexto mais geral [...]” e, portanto, “[...] pensar especificidades, singularidades e diversidades, não é pensá-las em si mesmas. Então, não é uma Amazônia isolada do mundo que se está a visualizar" (2016, p. 9). Portanto, é necessária a compreensão de que:

A percepção valorativa e respeitosa do diferente é, sem dúvida, um passo importante no caminho da superação de preconceitos, 
mas não pode ser confundida como ponto de chegada se o objetivo final é a construção de uma sociedade na qual as pessoas sejam tratadas sem distinção. E isto não pode ser confundido com a eliminação da diferença pela sua exclusão, até porque ser diferente não significa que também deva ser desigual [...] (COLARES; COLARES, 2011, p. 2).

Reforçando o enunciado, considera-se importante o alcance da equidade social, o fim da discriminação e a libertação de uma condição de inferioridade incutida na história, destacando que a diversidade cultural dos povos amazônicos precisa manter-se na égide da valorização, evitando a perda de uma "essencialidade amazônica". Afinal, a cultura é a manifestação mais visível de um povo, sem ela estes grupos estão fadados ao enfraquecimento de suas relações enquanto sujeitos sociais. Espera-se, portanto, que tais percursos contribuam no rompimento de uma visão banalizada, indicando que:

[...] é comum vermos a Amazônia brasileira retratada pela mídia como sendo somente uma rica floresta em processo de desmatamento, sofrendo pela ação dos seres humanos [...]. Retrata-se também a presença de inúmeras tribos indígenas, que são constantemente filmadas [...] e que viram documentários em produções estrangeiras por serem exóticos. Essa propaganda cria uma imagem onde as pessoas que não conhecem [...] a Amazônia [...] veem como imensas regiões alagadas, onde os moradores convivem, mesmo em zona urbana, com sucuris e jacarés (KLUSKA, 2016, p. 124-125).

Ultrapassando uma visão reducionista e discriminatória consolidada sobre a região, é válido destacar as inúmeras diversidades (ou manifestações delas) produzidas e difundidas no decorrer dos anos, dotando de significados a vida dos povos e construindo caminhos de valorização do local, com destaque para:

Danças: Marujada, Toada, Ciranda, Carimbó, Marambiré, Siriá, etc. Ritmos: Brega, Calypso, Batuque, Lundu, Lambada, Carimbó, etc. 
Culinária: Pato no tucupi, tacacá, tambaqui, pirarucu, etc.

Produtos típicos: Tucupi, tucumã, guaraná, cupuaçu, castanha, etc.

Medicina popular: pajés, benzedores, parteiras, ervas medicinais, etc.

Religiosidades: Tambor de Mina, Candomblé, Xamanismo, etc.

Mitos, lendas e contos: Curupira, Mapinguari, Cobra grande, Boto, Iara, etc.

Festivais amazônicos: Folclórico de Parintins, Tribos de Juruti, Ópera em Manaus, Sairé em Alter do Chão, Carnapauxis em Óbidos.

Ao elencar algumas das expressões culturais da região, torna-se possível vislumbrar diversas formas que representam a identidade amazônica, verificando movimentos grandiosos, como o Festival Folclórico de Parintins, tornando-se uma atração nacional, entre outros. Tais acontecimentos clareiam a ideia de uma perspectiva multicultural, uma vez que "[...] a construção do universo amazônico compõem-se de repletos sentidos e significados compostos por uma diversidade cultural, mas, ao mesmo tempo, singular", indicando assim que "[...] o Multiculturalismo está presente na diferença, que permite compreender a formação do povo da Amazônia brasileira, retratando sua igualdade ao mesmo em que retrata sua heterogeneidade cultural" (LOPEZ; NENEVÉ; AMARAL, 2013, p. 206).

Diante da complexidade do termo e da indefinição na literatura, recorre-se ao pensamento de Lopez, Nenevé e Amaral ao afirmarem que “[...] compreender o Multiculturalismo é perceber que existe o outro, e muitos outros dentro de uma sociedade, culturas, vocábulos, identidades variadas que contribuem para a formação de diversas organizações [...]" (2013, p. 208). Tal perspectiva poderá contribuir na compreensão histórico-social do papel de cada indivíduo amazônico para a constituição de um empoderamento e resistências contra toda e qualquer forma de opressão sobre as diferenças. Acredita-se que o enfoque do multiculturalismo, apesar de suas fragilidades, constitui caminhos para evidência e valorização das diversidades.

Outra problemática se mostra na representação da diversidade cultural no campo educacional, com a presença de um currículo oficial importado de outras realidades, além da presença de inúmeros sujeitos, diferentes entre si, em um mesmo espaço (a sala de aula), clareando gra- 
ves desafios como a formação de professores, ausência de materiais didático-pedagógicos específicos e a minimização dos saberes locais em detrimento do conhecimento sistematizado (universal), o que deveria ser o oposto, sem perder de vista a relação entre estes (COLARES; COLARES, 2016). Desse modo, o Quadro de No 2 apresenta dados sobre a Educação Escolar Indígena e Quilombola na Amazônia, especificamente, na região norte do país.

Quadro 2: Dados da Educação Escolar Indígena e Quilombola na região norte em 2018.

\begin{tabular}{|l|l|l|l|}
\hline \multicolumn{2}{|l|}{ EDUCAÇÃO INDÍGENA E QUILOMBOLA NA REGIÃO NORTE EM } \\
2018
\end{tabular}

Fonte: elaborado pelos autores com base no Anuário Brasileiro da Educação Básica, 2020.

Ao analisar o Quadro de $\mathrm{N}^{\circ} 2$ é visível um avanço quanto à incorporação da língua materna nos processos de ensino da Educação Escolar Indígena, apesar de estes não apresentarem informações quanto à disponibilidade de materiais didáticos específicos e sobre o tipo de formação que tem se propiciado a este grupo étnico. Por outro lado, referente à Educação Escolar Quilombola, os números revelam o enfraquecimento do compromisso com a formação, uma vez que há um grande percentual de estabelecimentos sem materiais específicos. Dessa última condição, associa-se a questão da diversidade cultural amazônica, sem instrumentos e subsídios capazes de proporcionar uma relação significativa entre a educação, os saberes locais e os conhecimentos universais, pois “[...] A Amazônia, em particular, é culturalmente diversificada, por esta razão faz-se necessário pensarmos em uma formação [...] que prepare [...] para lidar com esta situação [...]" (COLARES; COLARES, 2011, p. 5). 
Nesse sentido, a partir das discussões realizadas, elegemos três (3) distintos desafios sobrepostos à questão da Diversidade Cultural na Amazônia, os quais precisam ser destituídos em prol da melhoria da qualidade de vida, do reconhecimento, do respeito e da valorização dos povos locais e suas expressões culturais. Entre estes, destacam-se: 1) A condição histórica de inferioridade dos povos e da região; 2) A ideia de não pertencimento dos sujeitos amazônicos as suas raízes culturais; e 3 ) A ausência de subsídios que proporcionem a vivência das diversidades por estes indivíduos. Por conseguinte, apresentam-se algumas proposições sobre os itens elencados.

Concernente ao primeiro desafio, da condição histórica de inferioridade dos povos e da região, faz-se necessário e urgente romper com toda e qualquer ideologia que promova uma imagem negativa sobre a Amazônia, desviando de um paradigma excludente e reducionista. Para isso, recomenda-se a produção de estudos direcionados a um enfoque humano, dos modos de vidas, dos processos culturais e históricos, entre outros, percursos que evidenciem as particularidades locais. Assim, uma possível contribuição para superar este desafio se justifica na produção sistematizada dos conhecimentos locais por aqueles que estão inseridos nos espaços acadêmicos e educacionais. Para aqueles que não se sentem aptos à produção, uma alternativa viável se dá na busca por informações sobre a sua própria história, na inserção em grupos e na formação de lideranças locais, constituindo movimentos coletivos em prol dos direitos.

Este momento se configura como a Fase da Apropriação, onde o indivíduo deve incorporar-se de informações/conhecimentos sobre a sua realidade para, posteriormente, articular formas de lutas e resistências em prol de sua condição social. Nessa perspectiva, destaca-se a discussão de Colares e Colares em que:

Consideramos que para que possamos trilhar caminhos mais seguros na perspectiva de uma educação para a diversidade precisamos desenvolver práticas de questionamento do senso comum acerca das concepções e dos valores que alimentam os discursos de identidades e de diferenças. [...] Desvelar esta trama é da mais alta relevância para a superação das injustiças sociais [...] (2011, p. 9). 
O segundo desafio, referente à ideia de não pertencimento dos sujeitos amazônicos as suas raízes culturais, diz respeito à condição de distanciamento entre as gerações atuais e a sua própria cultura, assumida pelo grupo social ao qual estão inseridos. Essa realidade mostra-se visível em inúmeras manifestações culturais que foram se perdendo ao longo dos anos ${ }^{7}$, por não ter havido continuidade pelos mais novos, incutindo a imagem de rompimento do passado com o presente, onde a juventude (geração atual) prefere aquilo que vem de fora, proporcionado pela massificadora globalização. Assim, em grande parte dos movimentos culturais amazônicos, percebemos os mais velhos ainda na condução dos processos de organização destes. Logo, se não existe um pertencimento, a diversidade cultural tende ao desaparecimento no decorrer dos anos.

Um exemplo significativo, no que se refere ao sentimento de pertencimento, se mostra no estudo de Rodrigues (2018) ao evidenciar ações de valorização dos saberes locais, em uma terra indígena, e sua incorporação no currículo escolar como forma de preservação e resistência. Ações como estas reforçam a identidade de grupos sociais e corroboram na luta pela melhoria da qualidade de vida e da valorização cultural, momento em que os sujeitos passam a se conscientizar de seus papéis na transformação social. Portanto, o pertencimento torna-se condição para a preservação da diversidade. Eis que apresentamos a Fase da Inserção, processo em que o indivíduo insere-se em sua própria realidade, já consciente de seu dever e dotado de conhecimentos, assumindo o compromisso com a mantença de sua cultura e engajado na luta por valorização.

Por fim, o terceiro desafio, a ausência de subsídios que proporcionem a vivência das diversidades, adentra-se na questão do abandono e da vulnerabilidade social vivenciada pelos grupos humanos situados na Amazônia, principalmente, aqueles que estão em áreas de difícil acesso, como indígenas e quilombolas. Também reflete a ausência de elementos básicos que promovam qualidade no tratamento da diversidade cultural, necessitando de "[...] análise, avaliação e reformulação no campo teóricoconceitual das políticas [...]”, em busca de “[...] uma política pública edu-

\footnotetext{
${ }^{7}$ Para melhor compreensão da importância do resgate aos Saberes Culturais e Tradicionais amazônicos, sugerimos a leitura do estudo de Andrade (2014) sobre os contos populares da Amazô nia. Disponível em: http://www.ufopa.edu.br/portaldeperiodicos/index.php/revistaexitus/article/view/134.
} 
cacional na e da Amazônia e suas singularidades" (SOARES; COLARES; FERREIRA, 2020, p. 78). Desse modo, é fundamental a organização sistematizada dos sujeitos locais na luta por seus direitos básicos, ultrapassando a discriminação e incorporando-os como cidadãos.

Concomitantemente, apresentamos a Fase da Contraposição, momento em que os indivíduos, agora influenciados pelas duas fases anteriores (conscientes de seu papel, dispondo de conhecimentos e assumindo sua própria realidade), passam a reivindicar melhorias e direitos básicos, a organizar-se coletivamente e a questionarem, principalmente, os órgãos e condutores das políticas públicas, sobre as ausências visíveis em sua realidade. Esta é a última fase por que imbrica a condição de lutas de classes e empoderamento popular, em um movimento de ação e reflexão. Portanto, a prática social, como ponto de partida - ainda desconhecida na primeira fase - torna-se também o ponto de chegada - agora reformulada em detrimento do coletivo.

\section{Considerações Finais}

Inicialmente, é valido destacar a contribuição do estudo no sentido de vislumbrar avanços consideráveis no campo da produção científica, vivenciando-se, no tempo presente, um tipo de ruptura na região, abandonando a visão exótica e reducionista e adentrando em uma nova abordagem que dá ênfase aos aspectos humanos e suas identidades, escancarando condições desiguais perante os direitos públicos. No aspecto educacional, a existência de um currículo pré-definido, de âmbito externo, acaba por sucumbir os conhecimentos locais, excluindo a diversidade cultural de um lugar central no processo ensino-aprendizagem, na formação docente e nos materiais didático-pedagógicos. Soma-se a estes, uma série de outras condições enfrentadas pelos sujeitos amazônicos no decorrer de sua história e no enfraquecimento de suas culturas.

Em torno dessas problemáticas, acredita-se que o exercício de ação-reflexão (das fases) torna-se válido para a Amazônia no sentido de modificação dos sujeitos locais em detrimento de sua própria realidade, firmando-se como cidadãos de direitos. Por estes perpassam-se cami- 
nhos em prol da preservação, valorização, pertencimento, respeito e disseminação da cultura local, firmando-se no âmbito da própria essência identitária.

Desse modo, é perceptível que estamos diante de um longo caminho, cujas modificações precisam começar pela conscientização individual e, posteriormente, coletiva. Sem dúvidas, este deve ser o papel de cada estudante, pesquisador e/ou sujeito que se propõe a desmistificar o universo de singularidades presentes na Amazônia brasileira. Continuaremos juntos e fortalecidos em prol desta grande causa.

\section{Referências}

BORGES, Liliam Faria Porto. Educação, escola e humanização em Marx, Engels e Lukács. Revista Educação em Questão, v. 55, n. 45, jul./set., 2017, p. 101-126. Disponível em: https://periodicos.ufrn.br/educacaoemquestao/article/view/12747 Acesso em: 25 mai. 2020.

BRANDÃO, Carlos Rodrigues. A educação como cultura. Campinas, SP: Mercado de Letras, 2002.

BRASIL. Constituição da República Federativa do Brasil de 1988. Brasília, DF: Senado, 1988. Disponível em: http://www.planalto.gov.br/ccivil 03/ constituicao/constituicaocompilado.htm Acesso em: 20 mai. 2020.

CANEN, Ana. Educação multicultural, identidade nacional e pluralidade cultural: tensões e implicações curriculares. Caderno de Pesquisa, n. 111, 2000, p. 135-149. Disponível em: https://www.scielo.br/pdf/cp/n111/n111a07.pdf Acesso: 29 mai. 2020.

CHAUÍ, Marilena. Convite à Filosofia. São Paulo: Editora Ática, 2000.

COLARES, Anselmo Alencar. Amazônia: para além do território. In: COLARES, M. L. I. S; PEREZ, J. R. R; CARDOZO, M. J. P. B. (Org.). Educação e realidade amazônica - volume 3. Uberlândia: Navegando Publicações, 2018, p. 1 16. Disponível em: https://56e818b2-2c0c-44d1-8359-cc162f8a5934.filesusr.com/ugd/35e7c6 814b679c39cb4139be9cbb56b727c0fa.pdf Acesso em: 25 mai. 2020. 
COLARES, Anselmo Alencar; COLARES, Maria Lília Imbiriba Sousa. Apresentação (Amazônia: o universal e o singular). In: COLARES, A. A;

COLARES, M. L. I. S. (Org.). Educação e realidade amazônica. Uberlândia: Navegando Publicações, 2016, p. 11-23.

COLARES, Anselmo Alencar; COLARES, Maria Lília Imbiriba Sousa. Diversidade cultural: desafios educacionais no contexto amazônico. In: $25^{\circ}$ Simpósio Brasileiro de Política e Administração da Educação. São Paulo, 2011, p. 110. Disponível em: https://anpae.org.br/simposio2011/cdrom2011/PDFs/ trabalhosCompletos/comunicacoesRelatos/0068.pdf Acesso em: 31 mai. 2020.

DUPIN, Gisele. Para entender a convenção. Revista Observatório Itaú Cultural, n. 8, abr./jul., 2009, p. 13-28. Disponível em: http://d3nv1jy4u7zmsc.cloudfront.net/wp-content/uploads/itau_pdf/001516.pdf Acesso em: 01 jun. 2020.

GOMES, Nilma Lino. Educação e diversidade étnico-cultural. In: RAMOS, M. N.; ADÃO, J. M.; BARROS, G. M. N. Diversidade na Educação: reflexões e experiências. Brasília: Secretaria de Educação Média e Tecnológica, 2003, p. 6776. Disponível em: http://www.dominiopublico.gov.br/download/texto/ me002114.pdf Acesso em: 19 mai. 2020.

KLUSKA, C. A educação na Amazônia diante de suas singularidades. In: COLARES, A. A; COLARES, M. L. I. S. (Org.). Educação e realidade amazônica. Uberlândia: Navegando Publicações, 2016, p. 119-126.

LARAIA, Roque de Barros. Cultura: um conceito antropológico. Rio de Janeiro: Jorge Zahar, 2001.

LOPEZ, N.; NENEVÉ, M.; AMARAL, N. Por um ensino multicultural na Amazônia. Revista Igarapé, n. 2, 2013, p. 203-2018. Disponível em: http:// www.periodicos.unir.br/index.php/igarape Acesso em: 21 mai. 2020.

MOREIRA, A. F. B.; CANDAU, V. M. Educação escolar e cultura(s): construindo caminhos. Revista Brasileira de Educação, n. 23, mai./ago., 2003, p. 156-168. Disponível em: https://www.scielo.br/pdf/rbedu/n23/n23a11.pdf Acesso: 18 mai. 2020.

MUNANGA, Kabengele. A questão da diversidade e da política de reconhecimento das diferenças. Revista Crítica e Sociedade, v. 4, n. 1, 2014, p. 34-45. Disponível em: http://www.seer.ufu.br/index.php/criticasociedade/article/ view/26989/14725 Acesso em: 19 mai. 2020. 
MUNANGA, Kabengele. Algumas considerações sobre diversidade e a identidade negra no Brasil. In: RAMOS, M. N.; ADÃO, J. M.; BARROS, G. M. N. Diversidade na Educação: reflexões e experiências. Brasília: Secretaria de Educação Média e Tecnológica, 2003, p. 35-49. Disponível em: http://www.dominiopublico.gov.br/download/texto/me002114.pdf Acesso em: 19 mai. 2020 .

RODRIGUES, Gilberto César Lopes. Quando a escola é uma flecha: educação escolar indígena e territorialização na Amazônia. Revista Exitus, v. 8, n. 3, set./dez., 2018, p. 396-422. Disponível em: http://www.ufopa.edu.br/portaldeperiodicos/index.php/revistaexitus/article/view/65 Acesso em: 01 jun. 2020.

SANFELICE, José Luis. Prefácio. In: COLARES, A. A.; COLARES, M. L. I. S. Educação e Realidade Amazônica. Uberlândia: Navegando Publicações, 2016, p. 7-9.

SANTOS, José Luiz dos. O que é cultura. $6^{a}$ ed. São Paulo: Editora brasiliense, 1987.

SAVIANI, Dermeval. Prefácio. In: ESTÁCIO, M. A. F.; NICIDA, L. R. de A. História e educação na Amazônia. Manaus, AM: EDUA; UEA Edições, 2016, p. 1-3.

SOARES, Lucas de Vasconcelos; COLARES, Maria Lília Imbiriba Sousa; FERREIRA, Maria Antonia Vidal. Políticas educacionais na Amazônia: a questão "indígena" no ensino superior. Revista Teias, v. 21, n. 61, abr./jun., 2020, p. 68-80. Disponível em: https://www.e-publicacoes.uerj.br/index.php/revistateias/article/view/49558 Acesso em: 02 jun. 2020.

SOARES, Lucas de Vasconcelos; MELO, Wilverson Rodrigo Silva de. A educação na Amazônia no século XXI: um olhar crítico sobre as relações étnicoraciais na realidade escolar do município de Óbidos-Pará. In: COLARES, M. L. I. S.; COLARES, A. A.; RIBEIRO, A. A. M. (Org.). Educação e Realidade Amazônica: história, formação docente, tecnologia, política educacional e diversidade cultural. Santarém: UFOPA, 2017, p. 87-100. Disponível em: https://drive.google.com/file/d/ 1a0IqE0cXzOkOkvmCanmryRaHJf4JPtmL/view Acesso em: 29 mai. 2020.

UNESCO. Declaração universal sobre a diversidade cultural, 2001. Disponível em: http://www.unesco.org/new/fileadmin/MULTIMEDIA/HQ/ CLT/diversity/pdf/declaration_cultural diversity_pt.pdf Acesso em: 20 mai. 2020. 
UNESCO. Convenção Para Proteção e Promoção da Diversidade das Expressões Culturais, 2007. Disponível em: http://www.ibermuseus.org/wpcontent/uploads/2014/07/convencao-sobre-a-diversidade-das-expressoes-culturais-unesco-2005.pdf Acesso em: 20 mai. 2020.

\section{Sites consultados:}

Dicionário On-line de Português. Dicio, 2009. Disponível em: https:// www.dicio.com.br/diversidade/ Acesso em: 30 mai. 2020.

IMAZON. A Amazônia em números. 2013. Disponibilidade em: https:// imazon.org.br/imprensa/a-amazonia-em-numeros/Acesso em: 01 jun. 2020. 
